\title{
Progress in ultrasonic tendon duct imaging
}

\author{
Martin KRAUSE ${ }^{1}$, Klaus MAYER ${ }^{2}$, Martin FRIESE $^{3}$, Boris MILMANN ${ }^{4}$, Frank \\ MIELENTZ $^{5}$, Gregor. Ballier ${ }^{6}$
}

${ }^{1}$ Affiliation $1^{\text {st }}$ and $3^{\text {rd }}$ to $5^{\text {th }}$ author, Berlin, Germany, martin.krause@bam.de

${ }^{2}$ Affiliation $2^{\text {nd }}$ and $6^{\text {th }}$ author, Kassel, Germany

\section{Abstract}

Ultrasonic imaging of tendon ducts enables the precise localisation of grouting faults in many cases. Additionally to well known criteria for detecting grouting faults in tendon ducts new possibilities were developed recently: Phase value evaluation for qualitative distinction between steel and air reflection and analysing backscatter from the area of bottom side of tendon ducts.

The application of linear array technique enables much faster data acquisition and data analyses. Examples and comparison with automated scanning measurement including phase value analysis are presented.

Two main effects influence the complex behaviour of wave propagation and reflection:

- Different arrangement and number of strands or internal rebars

- Superposition of reflecting signals and wave modes propagation in the interface around the tendon duct.

In order to understand the experimental results, EFIT modelling is performed (EFIT: Elastodynamic Finite Integration Technique). From this synthetic ultrasonic echo data are calculated. They are used as data sets for reconstruction calculation with SAFT (Synthetic Aperture Focusing Technique). These results are compared to SAFT reconstruction calculation of the measured data in order to analyse the influences of the filling condition of the duct on the propagation of the elastic waves.

\section{Résumé}

La méthode d'écho ultrasonore en combinaison avec des calculs de reconstruction permet la localisation précise des inclusions d'air dans des tubes du béton précontraint. Récemment la nouvelle possibilité d'analyse de phase est appliquée. De plus, l'application d'un réseau linéaire permet de mesurer les données beaucoup plus rapidement. Des exemples sont décrits.

Pour mieux comprendre les résultats et préciser les règles pour identifier des défauts, la modélisation des ondes élastiques par intégration est appliquée (EFIT: Elastodynamic Finite Integration Technique). Avec des calculs de ce type, des données ultrasonores synthétiques sont produites, servant comme base pour une reconstruction (SAFT; Synthetic Aperture Focusing Technique). La comparaison de la modélisation avec les résultats expérimentaux précise les critères pour l'évaluation d'état de l'intérieur des tubes.

\section{Keywords}

Prestressed concrete structures, reconstruction calculation, SAFT, EFIT Modelling

\section{Introduction}

Ultrasonic imaging technique allows localization of grouting faults in tendon ducts. The most established way to do this is the synthetic aperture approach. The data is measured in a 2D-area of the surface and the reflected signals are imaged as B-scans and C-scans, respectively. In most cases the data is evaluated by a $2 \mathrm{D}$ - or $3 \mathrm{D}$ - reconstruction calculation 
(SAFT, Synthetic aperture Focusing Technique) and FT-SAFT (Fourier Transform SAFT) $[1,2]$. It results in a three dimensional representation of the reflections from the inside of the reflected volume. The imaging is performed by sections and projections in these data sets. The longitudinal and cross sections (also called SAFT-B-scans) and the depth section parallel to the surface (SAFT-C-scans) represent the exact location of the tendon duct and allow analysing the grouting condition.

Actually most practical applications at post-tensioned concrete structures are performed with dry point contact transducers (12 transmitting and 12 receiving transducers) [3]. The centre frequency is $55 \mathrm{kHz}$ corresponding to wavelength of about $40 \mathrm{~mm}$ in concrete. The measuring technique works automatically applying scanning systems. In order to accelerate the ultrasonic data acquisition a linear array was developed recently [3]. Additionally to 3Devaluation of such linear array measuring results [8] a comparison of phase analysis between scanning and linear array measurements is presented in this paper.

Taking into account both, intensity and phase value of the signals reflected from the top side of the tendon duct, allows distinction between well-grouted areas and grouting defects $[4,5]$ :

1 In the magnitude representation air inclusions show significant higher reflection intensity (total reflection) than for grouted steel rebars or strands.

2. In imaging the phase value or signal shape of the reflected signal the distinction between air filled areas and grouted steel bars or strands is realized by the phase difference of $180^{\circ}$.

A third effect is known from several measuring results at tendon ducts: In several cases reflecting signals are appearing in the SAFT-B-scans corresponding to the depth of the bottom side of the tendon duct. In order to investigate, whether this type of signal can reliably be applied to distinguish between grouted and ungrouted areas, the propagation of elastic waves is calculated for different arrangements of tendon ducts with and without air inclusions. These calculations are carried out applying EFIT (Elastodynamic Finite Integration Technique), a well-established modelling tool for understanding wave propagation in concrete structures [7].

\section{Ultrasonic Imaging: Fast Measurement}

In order to accelerate the ultrasonic data acquisition, a linear array was developed in cooperation between BAM and ACSYS (Kozlov et al. 2006). It consists of 10 lines à 4 dry contact shear wave transducers working with $50 \mathrm{kHz}$. The distance of the lines is $35 \mathrm{~mm}$ in the present modification. The transducers and the electronics are mounted in a handheld box easily to be applied at concrete surfaces. The ten lines are switched as a multistatic array, that means one line acts as transmitter and all others as receivers, then the second as transmitter, and so forth as shown in figure 1 (left). The data transfer is organized in the way that the whole data set is measured and stored in less than one second per location.

The data measured along a line can be combined to one data set and are evaluated with fast FT-SAFT reconstruction calculation. Together with 3D imaging technique the scatterers and reflectors in the volume of interest can quickly be analyzed on site with cross and longitudinal sections as well as depth sections and phase evaluation (corresponding to ultrasonic SAFT-B- and C-scans)[4]. 

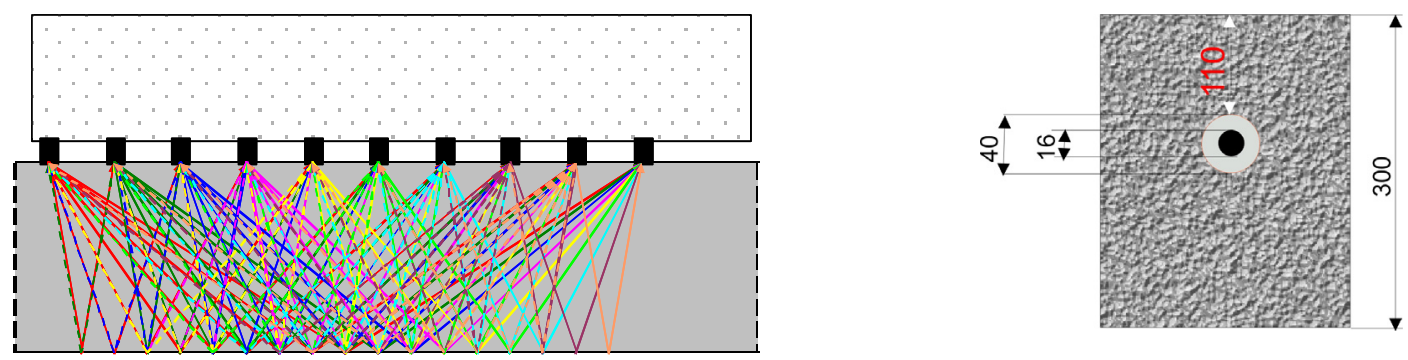

Figure 1. Left: Measuring principle Linear Array;

right: sketch of tendon duct D1 from large concrete slab of BAM

In order to assess the capability of the new linear scanner in comparison with the automated scanner with T/R-probe test series were performed. The measurements were carried out at a BAM test site. It is the so called large concrete slab (LCS) with several tendon ducts containing numerous well defined artificial grouting faults constructed for comparative tests described elsewhere $[9,4]$. As example figure 2 presents the result for a tendon duct with a diameter of $40 \mathrm{~mm}$ and a concrete cover and geometry as depicted in figure 1 (right). This tendon duct is named D1 as in paper [4].

The phase value representations $2 \mathrm{c}$ indicates a clear phase value difference between the two ungrouted areas 1 and 2 and the grouted areas (approx. $180^{\circ}$ for the grouted areas and approx $0^{\circ}$ for the air inclusions in void 2 and partly in void 1). Probably there are additional unintended air inclusions at the top side of the duct between $\mathrm{x}=1200 \mathrm{~mm}$ and $1600 \mathrm{~mm}$, which are not thick enough to be indicated by $\gamma$-radiography.

In conclusion both measuring methods show principally similar results. That means the advantage of faster handheld measurement by means of linear array can be used for magnitude and phase evaluation.

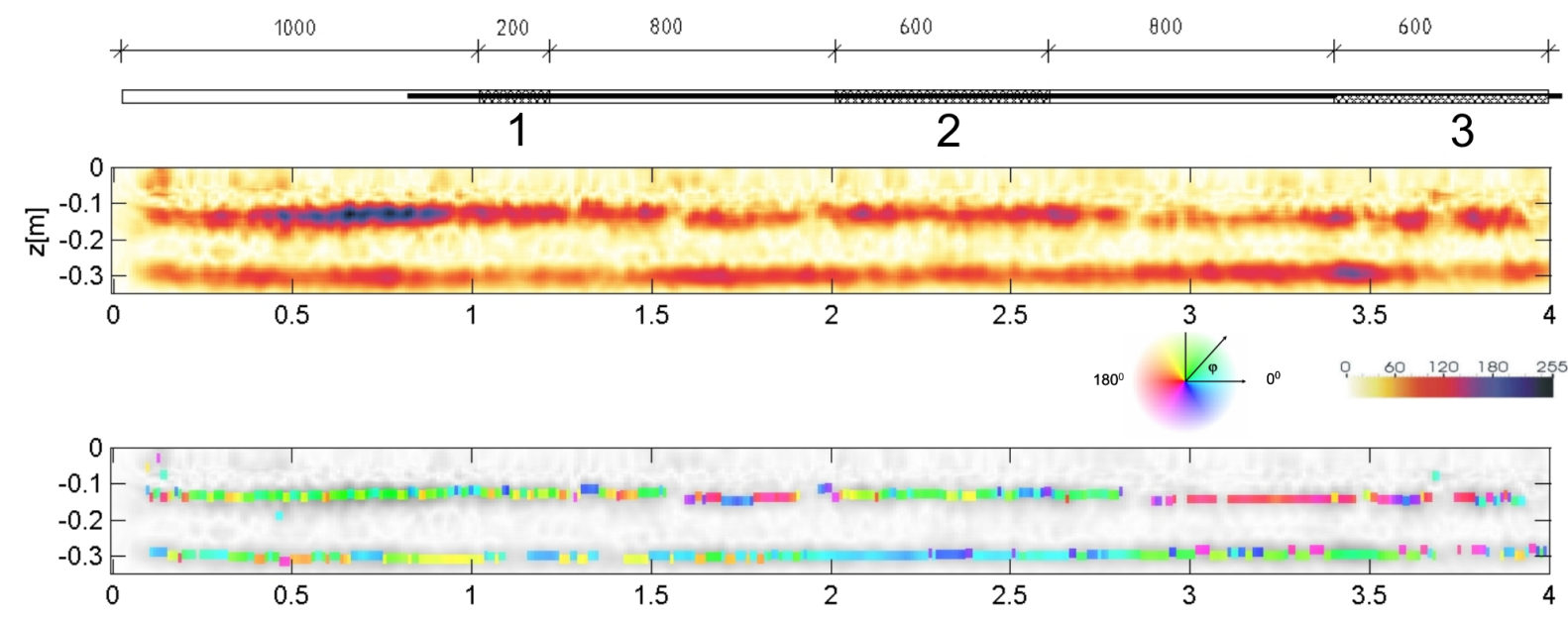

Figure 2. Comparison of ultrasonic imaging of tendon duct by automated T/R scanning and Linear Array measurement

a) Location of grouting faults, verified by $\gamma$-radiography

b) Magnitude Linear Array c) Phase value Linear Array 


\section{Ultrasonic Imaging: Signals from the "bottom side" of tendon ducts}

From several measuring campaigns with ultrasonic imaging it is known that signals arrive from the topside as well as from the bottom side of tendon ducts. Up to now it is not clear which part of this signal is caused by backscatter from the interior of the duct and from wave modes travelling around the duct. First this was discovered in measuring the so-called specimen FBS 1, where the first systematic imaging studies on tendon ducts were carried out [10]. In order to analyse the origin of these reflecting signals, the dependence on tendon diameter is listed for 5 examples in table 1 . Two of the examples are depicted in figures 3 and 4.

From the table and the examples it can be read that the difference between top and bottom signal doesn't correspond neither to the diameter of the duct nor to the perimeter. Additionally it isn't stable for a certain tendon duct type. So in table 1 the span of the extreme values is listed. The signal appears 1.1 and 1.5 times deeper than the duct diameter.

In cases where it was possible to verify the grouting condition of the ducts investigated in bridges well grouting was confirmed. Otherwise it is known from previous work that rotating creeping waves around the duct mainly appear for ungrouted ducts [4]. Penetrating waves are especially influenced by inner duct conditions but may additionally cause surface waves at the surrounding interface. Following these questions several cases were investigated by EFIT modelling and are described in the following section.

Table 1. Depth of reflecting signals of tendon ducts in different specimens and structures

\begin{tabular}{|c|c|c|c|c|}
\hline & $\begin{array}{c}\text { Duct Diameter } \\
\text { in } \mathrm{mm}\end{array}$ & $\begin{array}{c}\text { Concrete cover } \\
\text { top side }(\mathrm{mm})\end{array}$ & $\begin{array}{c}\text { Depth of bottom } \\
\text { side signal }(\mathrm{mm})\end{array}$ & $\begin{array}{c}\text { Difference } \\
\text { in } \mathrm{mm}\end{array}$ \\
\hline FBS 1 & 85 & 267 & 380 & 113 \\
\hline FBS 2 & 85 & 267 & 364 & 97 \\
\hline Railway Bridge & 45 & $167 \ldots 180$ & $242 \ldots 246$ & $66 \ldots 75$ \\
\hline Road bridge & 100 & $341 \ldots 461$ & $490 \ldots 566$ & $105 \ldots 149$ \\
\hline Viaduct & 65 & $204 \ldots 225$ & $273 \ldots 306$ & $69 \ldots 81$ \\
\hline
\end{tabular}
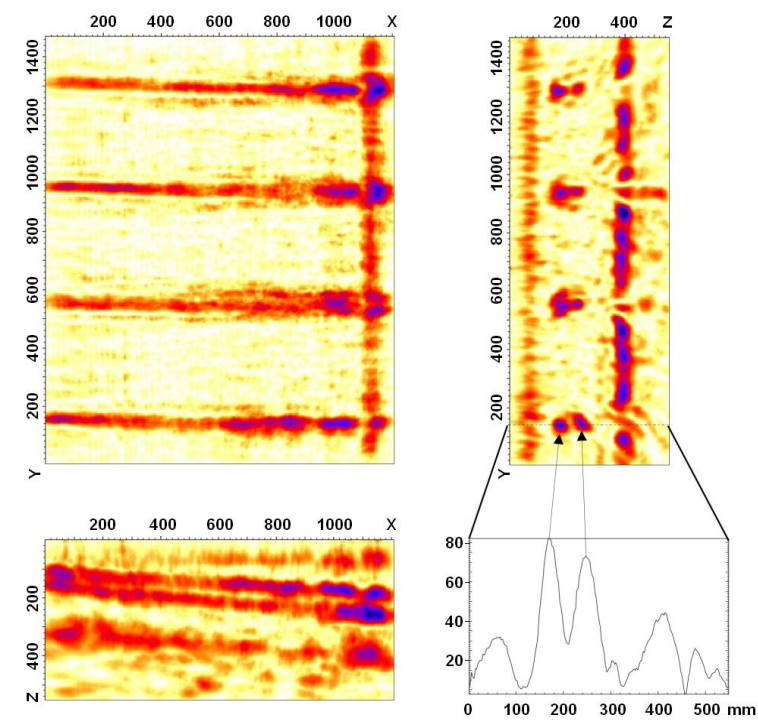

Figure 3. Ultrasonic imaging of tendon ducts in a railway bridge 


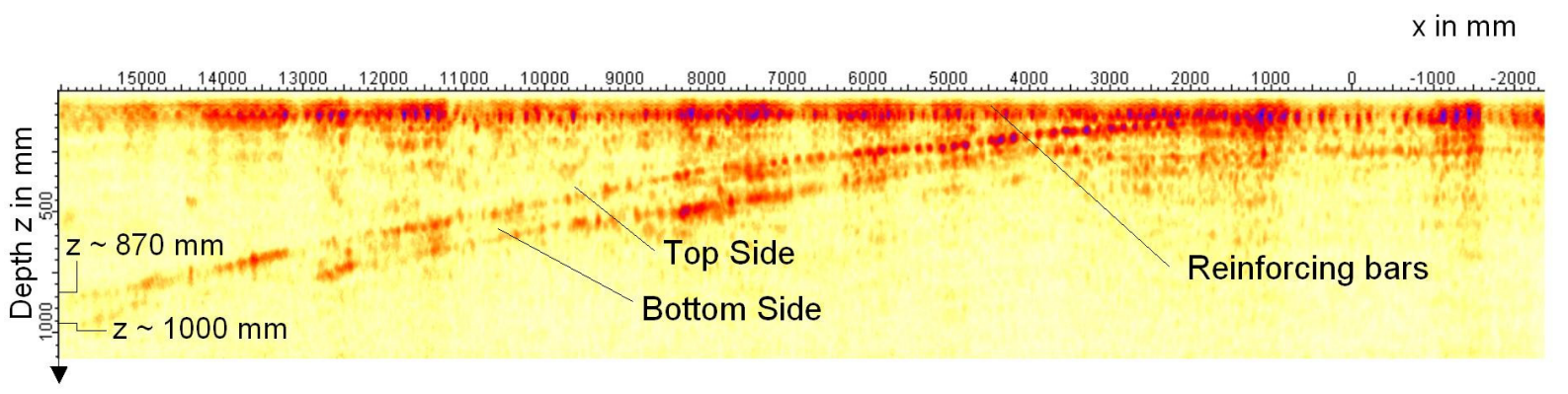

Figure 4. Example road bridge: Top and so called bottom side signal of tendon duct (diameter $100 \mathrm{~mm}$ ), magnitude representation

\section{Modeling ultrasonic wave propagation in and around tendon ducts}

\subsection{Principle of EFIT Modeling}

Modeling was performed applying software developed at University of Kassel, which uses the 2D- and 3D-EFIT - Code (2D- and 3D- Elastodynamic Finite Integration Technique (EFIT) [11], [12]. It is an implementation of the finite integration time domain method for the discretization of the elastodynamic field equations and uses a discretization of the elastic properties of the material and the vector field quantities in a range of $1 / 10$ of the wavelength. Therefore at least for 3D simulation huge computational memory is necessary which is realized by parallel computing on the base of the Message Passing Interface (MPI) standard

\subsection{Application for different conditions of tendon ducts}

For best understanding of experimental results in a first step propagation of elastic waves in and around a duct is calculated by applying 2D EFIT. First the proper filling conditions are investigated separately: air, pure mortar, pure steel, and then steel rebar in the duct and strands. Finally air inclusions are added.

$40 \mathrm{~mm}$ and $100 \mathrm{~mm}$ diameter tendon duct are placed in concrete with concrete cover of $100 \mathrm{~mm}$ and $150 \mathrm{~mm}$, respectively. The EFIT ultrasonic "experiment" is realized applying a $100 \mathrm{kHz}$ shear wave transducer placed perpendicular above the tendon. The polarisation of shear waves is orientated in the paper plane (SV-arrangement).

In the following some main results are briefly summarized. Figure 5 depicts snap shots of wave propagation and SAFT reconstruction for 3 different tendon states: air filled, grouted with steel rebar and pure mortar. The SAFT reconstructions are applied to synthetic data obtained by moving the transducer along a line above the tendon.

Common aspects: The shear wave point contact transducer emits a Rayleigh wave at the surface and p-waves with an angle of about $45^{\circ}$. They are not further discussed. In all SAFT reconstructions the first multiple echo from reflection at the top side of the duct appears at about $\mathrm{z}=300 \mathrm{~mm}$.

Air filled duct: The shear wave reflection at the top side of the duct is intense. In the moment of the selected snapshot it nearly reaches the top side. Creeping shear waves revolve around the duct in both directions. The snapshot shows the moment before their crossing at the bottom side of the duct. They emit energy continuously, which is also measured at the surface. In the SAFT reconstruction principally three maxima are visible: The reflex at the topside, the surrounding creeping wave at $\mathrm{z}=280 \mathrm{~mm}$ and the first multiple echo at $300 \mathrm{~mm}$.

Duct with rebar: The shear wave reflection is less intense than at air as expected. Partly the shear wave continues propagating in steel and is reflected at the bottom side of the duct. This appears as signal in the SAFT-reconstruction at $\mathrm{z}=240 \mathrm{~mm}$, because of faster wave 
propagation in steel. In the phase representation of the first reflex it is $180^{\circ}$ shifted relative to the reflex at air (left side) as expected. Otherwise the phase of the bottom reflex is similar to the first reflex. The signal at $300 \mathrm{~mm}$ is the first multiple of the top side reflex whereas the signal at $\mathrm{z}=270 \mathrm{~mm}$ is probably caused by mode conversion from internal reflected shear waves running at the interface duct/concrete.

\section{$100 \mathrm{~mm}$ duct air filled} (steel sheet $0.5 \mathrm{~mm}$ thick)
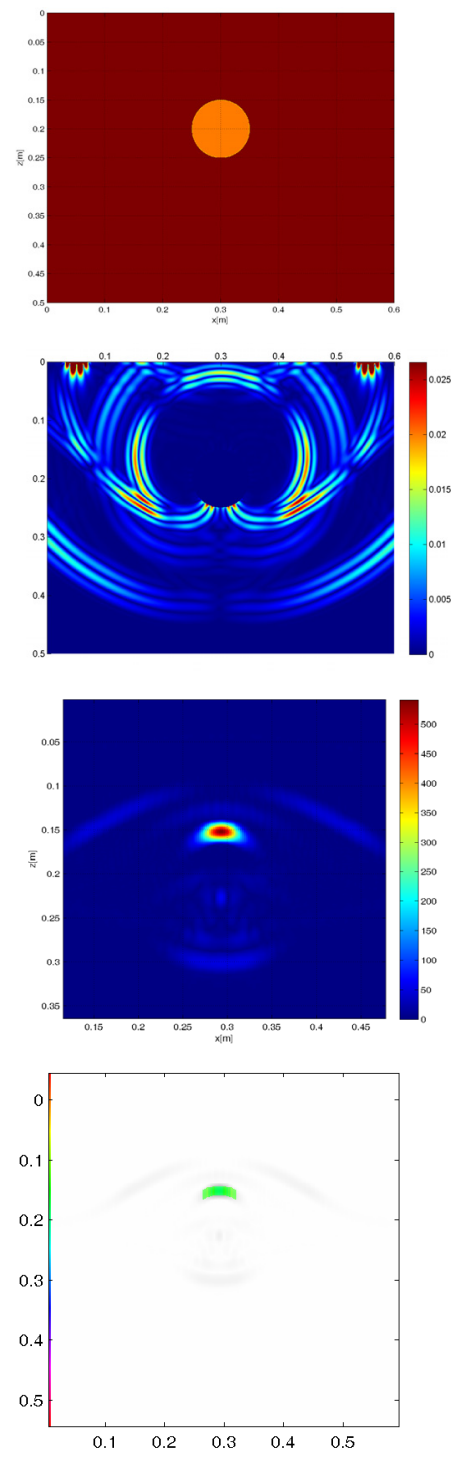

$100 \mathrm{~mm}$ duct with steel bar $90 \mathrm{~mm}$ steel centered, grouted
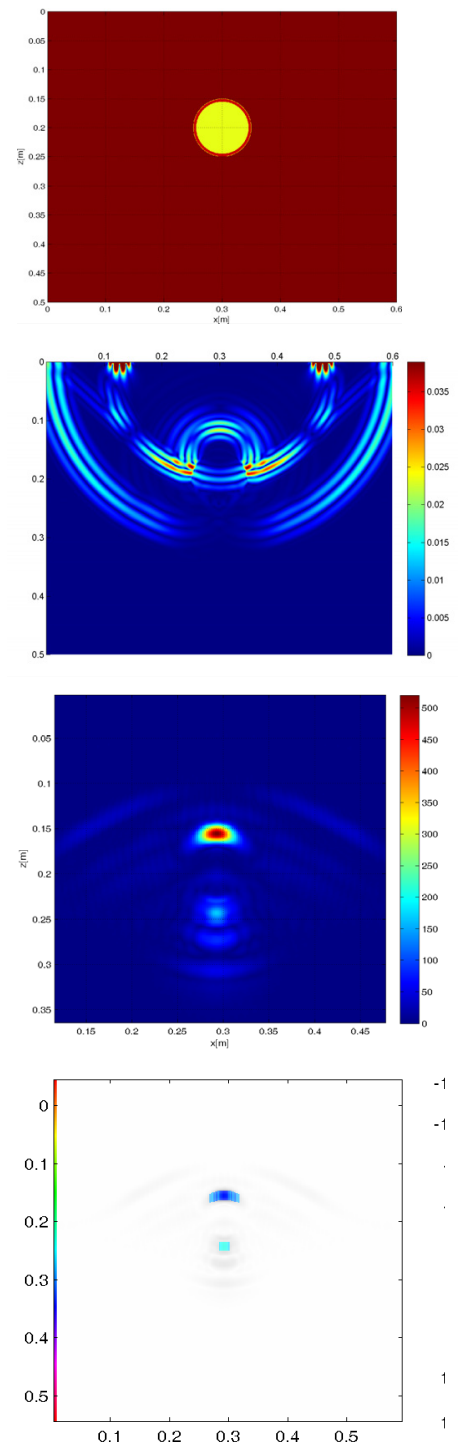

$100 \mathrm{~mm}$ mortar
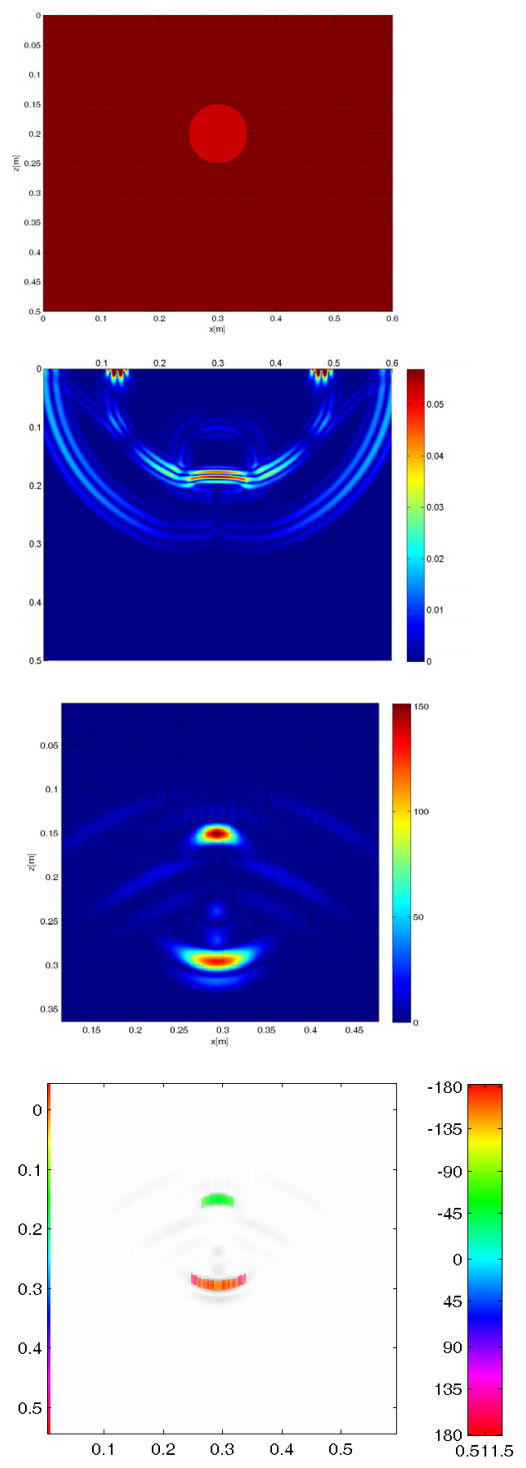

Figure 5. EFIT modelling of wave propagation for different filling conditions of a $100 \mathrm{~mm}$ tendon duct. Line 1: arrangement of duct; line 2: snapshot of wave propagation( air: after $100 \mu \mathrm{s} ;$ steel and mortar after $70 \mu \mathrm{s})$; line 3,4: SAFT reconstruction of artificial ultrasonic measuring signals (3: magnitude, 4: phase value)

Mortar: In case of mortar the reflection at the top side of the duct is weak because of similar acoustic impedance. Since the slope of the duct and the slower wave propagation velocity in mortar cause a kind of focusing of the wave front towards the bottom side of the tendon. Thus the reflecting intensity is nearly as intense as at the top side (see SAFTreconstruction). The bended form of the reflecting line in the reconstructed image probably is 
caused by the fact that elastic waves penetrate into the duct from many directions without important loss. The phase value of the top reflection corresponds to air reflection (smaller acoustic impedance).

Wave propagation and reconstruction of grouted tendons containing strands show principally similar signal structure, which is an overlay of backscatter, mode conversion and transmission at steel and mortar, respectively. However the intensity of reflected pulses doesn't correspond to experimental results. It is assumed that additional geometric conditions as strand locations, diameter of strands, geometry of tendons as well as angle of incidence and interference of different wave modes play an important role. For specifying knowledge further studies including 2D- and 3D-modelling and experiments for exactly known tendon duct geometries will be performed.

\section{Conclusions}

The results described in this paper present advantages in applying ultrasonic imaging for analyzing tendon ducts in post-tensioned concrete structures.

It is demonstrated that fast ultrasonic measurement with an ultrasonic linear array allows analysing tendon ducts as precisely as automated scanning with transmitter/receiver sensor heads. Thus handheld measurement with linear array is applicable in limited areas for fast imaging of tendon ducts including phase evaluation for localising grouting faults.

Results obtained at post tensioned concrete bridges have shown that additionally to reflecting signals from the top side of tendon ducts often deeper signals appear for well grouted ducts. In order to analyse their origin EFIT modelling of different arrangements and grouting conditions was performed. It can be assumed that the presence of grouting mortar causes reflections from the bottom side of tendons, which appear deeper in the imaging result because of slower wave propagation in mortar. In contrast the high intensity of such signals in experiments is not yet explained. Further research work in this point is necessary taking into account the exact geometry of tendons.

\section{Acknowledgements}

The support of this study by Deutsche Forschungsgemeinschaft (DFG; German Research Foundation) is gratefully acknowledged. Railway bridge investigations were funded by the $6^{\text {th }}$ European framework program (Sustainable Bridges [13]).

\section{References}

1. Schickert, M., Krause, M. and W. Müller: Utrasonic Imaging of Concrete Elements Using Reconstruction by Synthetic Aperture Focusing Technique.Journal of Materials in Civil Engineering (JMCE), ASCE Vol. 15 (2003) 3, pp. 235-246.

2. Streicher, D., Algernon, D., Wöstmann, J., Behrens, M. and H. Wiggenhauser: Automated NDE of post-tensioned concrete bridges sing imaging echo methods. In: Proceedings of the 9th European conference on NDT, 25-29 September 2006. BB 103-CD, e.1.3.1. DGZfP, Berlin (2006).

3. Kozlov, V.N., Samokrutov, A.A. and V.G. Shevaldykin: Ultrasonic Equipment for Evaluation of Concrete Structures Based on Transducers with Dry Point Contact. In: AlQuadi, I. and G. Washer (eds.); Proceedings of the NDE Conference on Civil Engineering, 14.-18. August 2006, St. Louis, MO, USA, pp. 496-498.

4. Krause, M., Milmann, B., Mielentz, F., Streicher, D., Redmer, B., Mayer, K., Langenberg, K.-J. and M. Schickert: Ultrasonic Imaging Methods for Investigation of Post-Tensioned Concrete Structures: A Study of Interfaces at Artificial Grouting Faults and its Verification, Journal of Nondestructive Evaluation (2008) 27, pp. 67-82. 
5. Mayer, K., Langenberg, K.-J., Krause, M., Milmann, B. and F. Mielentz: Characterization of Reflector Types by Phase-Sensitive Ultrasonic Data Processing and Imaging. Journal of Nondestructive Evaluation 1-3 (2008) 27, pp. 35-45.

6. Krause, M., Mielentz, F., Milmann, B., Streicher, D. and K. Mayer: Ultrasonic reflection properties at interfaces between concrete, steel and air: imaging and modelling. In: AlQuadi, I. and G. Washer (eds.); Proceedings of the NDE Conference on Civil Engineering, 14.-18.08.2006, St. Louis, MO, USA, pp. 472-479.

7. Marklein, R.: The Finite Integration Technique as a general tool to compute acoustic, electromagnetic, elastodynamic and coupled wave fields. In: Stone, W.R. (ed.) ; Review of Radio Science 1999-2002. IEEE Press, New York (2002).

8. Krause, M., Gräfe, B., Mielentz, F., Milmann, B., Friese, M., Wiggenhauser, H. and K. Mayer: Ultrasonic Imaging of Post-tensioned Concrete Elements: New Techniques for Reliable Localization of Grouting Defects. In: Alexander, M. G., Beushausen, H.-D., Dehn, F. and P. Moyo (eds.); Proceedings of the Concrete Repair, Rehabilitation and Retrofitting II, ICCRRR 2008, 24.-26.11.2008, Kapstadt, CD-ROM, pp. 521-527.

9. Taffe, A., Borchardt, K. and H. Wiggenhauser: Specimen for the improvement of NDTmethods - Design and construction of a Large Concrete Slab for NDT methods at BAM. In: DGZfP (ed.); International Symposium Non-Destructive Testing in Civil Engineering (NDT-CE) in Berlin, Germany, September 16-19, 2003, Proceedings on BB 85-CD, P11, Berlin (2003).

10. Krause, M., Mielentz, F., Milmann, B., Streicher, D. and W. Müller: Ultrasonic imaging of concrete elements: State of the art using 2D synthetic aperture. In: DGZfP (ed.); International Symposium Non-Destructive Testing in Civil Engineering (NDT-CE) in Berlin, Germany, September 16-19, 2003, Proceedings on BB 85-CD, V51, Berlin (2003).

11. Mayer, K., Marklein, R., Langenberg, K.J. and T. Kreutter: Three-dimensional imaging system based on Fourier transform synthetic aperture focusing technique. Ultrasonics $\mathbf{2 8}$ (1990) 241-255.

12. Marklein, R.: The Finite Integration Technique as a general tool to compute acoustic, electromagnetic, elastodynamic and coupled wave fields. In: Review of Radio Science 1999-2002. W.R. Stone (ed.); IEEE Press, Piscataway 2002.

13. Niederleithinger E. and R. Helmerich: New methods for inspection and condition assessment. In: Bien, J., Elfgren, L. and J. Olofson (eds); Sustainable Bridges Assessment for future Traffic Demands an Longer Lives, DWE, Wroclaw, Poland 2007. 